face-to-face events to enable deeper discussion of shared challenges and solutions.

Impact Since launching in 2015 the website has had more than 70 resources, over 1100 registered users and a growing community of Champions. To maintain the wider network there are bi-monthly webinars to discuss diverse medication safety topics. These webinars have raised safety issues that have gone on to shape national strategy via the RCPCH. They are accessed frequently on YouTube. There have been a series of well-attended MedsIQ events hosted at the RCPCH to bring clinicians, families and researchers together to discuss medication safety. Through these events MedsIQ has been able to work closely with families and the public to support safe administration of medicines within the community.

Where next? In direct response to topics raised at MedsIQ events and webinars, the MedsIQ team are working closely with their partners, Wellchild and Medicines for Children, to help develop a new app to support families to manage medications in the home environment. This app is due to launch in March 2019.

Following the success of MedsIQ, the RCPCH is launching QI central, a website that extends the MedsIQ concept to all areas of paediatric Quality Improvement. This website launches in March 2019.

\section{P188 RADIOGRAPHIC ABNORMALITIES IN CHILDREN HOSPITALIZED WITH ACUTE ASHMA}

Leina Ahmed*, Babu Paturi. Our Lady of Lourdes Hospital, Drogheda, Ireland

10.1136/archdischild-2019-epa.543

Introduction Acute asthma exacerebation is a common cause of children admissions. Chest $\mathrm{x}$-ray is not part of routine acute asthma management, but may be performed in some cases. A chest radiograph should be performed if there is subcuatanous emphysema, persistent unilateral sign, or in life threatening asthma(Emergency Paediatrics asthma GuidelineRCPI-HSE).

Aim To find out the outcome of the chest $x$-rays in children admitted with acute asthma, and its conribution in the management plan.

Methods

- A retrospective chart review.

- Inclusion criteria: Children 5-16 years admitted with acute asthma, had chest $\mathrm{x}$-ray.

- Place: Paediatrics ward, Our Lady of Lourdes Hospital, Drogheda.

- Period: the year 2017.

- Sample size: 28 children.

\section{Results}

- Two third of children included in the audit were males, one third were females.

- One third of patients were admitted in September, the rest were admitted in the other months.

- About three quarter of x-rays were performed during the evening and night shifts.

- Two third of x-rays were performed within 3 hours of ED attendance.
- Half were indicated by poor response to initial treatment (increased respiratory effort, oxygen requirement).

- Around one third of the x-rays showed elements of infection. Antibiotics were prescribed to two third of patients.

- Two third of the patients had previous x-rays.

\section{Discussion}

- Chest X-rays may be benifecial in some cases where presence of another lung pathology can have negative effect on the response to asthma treatment.

- Two third of children were unnecessarly exposed to radiation. Two third received antibiotics in the abscence of evidence of infection, this has impact on patients safety.

\section{Recommendations}

- Adherence to HSE guideline in acute asthma management.

- Minimize unnecessary investigation in acut asthma.

- Patient safety should be a priority when taking management decisions.

\section{P189 ADMISSION RATES TO NICU FROM ASSISTED DELIVERIES}

Rebecca Russell ${ }^{*}$, Aisling McCann. Department of Neonatology, National Maternity Hospital, Holles Street, Dublin, Ireland

\subsection{6/archdischild-2019-epa.544}

Aim Our aim was to determine admission rates to the neonatal ICU from operative vaginal deliveries(OVDs) as well as elective and emergency Caesarean sections(C/S). By completing this audit we aimed to establish the need for Paediatric SHO presence at the above deliveries.

Methods Our study period was the month of February 2018. We excluded all births under 35 weeks gestation who would qualify for an automatic admission to the NICU. Our study population included any infants born by either elective/emergency CS and OVDs. We obtained our data set from Medical records and isolated our study population. Using the electronic medical record we determined the mode of delivery, reason for same and if an admission to NICU was required within in the first 4 hours of life.

Results In the study period there were 561 live births. 213 infants were delivered by either $\mathrm{C} / \mathrm{S}$ or OVD. There were 77 OVDs and $136 \mathrm{C} / \mathrm{S}$, which could be further broken down into 69 Emergency $\mathrm{C} / \mathrm{S}$ and 67 Elective. Of the OVDs 16 patients were admitted to the NICU giving an overall admission rate of $22 \%$. Interestingly both $\mathrm{C} / \mathrm{S}$ populations showed the same number of admissions;10 per group.

Conclusion As Neonatal SHO's we are required to attend all $\mathrm{C} / \mathrm{S}$ as well as OVDs. The above data shows no difference between the admission rates of infants born by emergency versus elective $\mathrm{C} / \mathrm{S}$. However, the admission rate of infants born by OVD is 1 in 5 . From this audit it could be determined that there is a continued need for Paediatric assistance at above deliveries however there is the need for further investigation into the timing and reason for above admissions. Going forward we would like to compare the above figures with admission rates to NICU from Spontaneous Vaginal Deliveries. 